\title{
BMJ Open Pregnancy-associated outcomes in women who spent some of their childhood looked after by local authorities: findings from the UK Millennium Cohort Study
}

\author{
Stella K Botchway, Maria A Quigley, Ron Gray
}

To cite: Botchway SK, Quigley MA, Gray R. Pregnancy-associated outcomes in women who spent some of their childhood looked after by local authorities: findings from the UK Millennium Cohort Study. BMJ Open 2014:4:e005468. doi:10.1136/bmjopen-2014005468

- Prepublication history for this paper is available online. To view these files please visit the journal online (http://dx.doi.org/10.1136/ bmjopen-2014-005468).

Received 14 April 2014 Revised 4 September 2014 Accepted 5 September 2014

CrossMark

\section{National Perinatal}

Epidemiology Unit, Nuffield Department of Population Health, University of Oxford, Oxford, UK

Correspondence to Dr Stella K Botchway; stella.botchway@nhs.net

\section{ABSTRACT}

Objectives: There has been very little description of the health and social outcomes at pregnancy and early motherhood of girls who were previously looked after by local authorities. The objectives of this study were to compare the sociodemographic and health profiles of mothers who had spent time in a children's home or with foster parents as a child to mothers who had not. In particular, to examine associations between being looked after and the likelihood of smoking during pregnancy, birth weight, the presence of symptoms of maternal depression and the initiation of breastfeeding.

Design: A retrospective cross-sectional study using the baseline questionnaire of the Millennium Cohort Study.

Setting: The UK.

Participants: A nationally representative study of 18492 mothers of babies born in the UK during 2000-2002.

Exposure: A history of spending time in a children's home or with foster parents.

Outcome measures: (1) Smoking during pregnancy; (2) low birth weight; (3) symptoms of maternal depression and (4) initiation of breastfeeding.

Results: In univariable analyses, women who had been looked after by local authorities were significantly less likely to be of a higher social class, live in a highincome household or have achieved a high level of education. They were more likely to have a lowbirthweight baby and be a single parent. In multivariable analyses, women who had been looked after by local authorities were more likely to smoke during pregnancy (adjusted OR $3.095 \% \mathrm{Cl} 2.14$ to 4.3) and were more likely to have symptoms of depression (adjusted OR $1.9895 \% \mathrm{Cl} 1.4$ to 2.7 ) compared with women who had not been looked after. Conclusions: Our results suggest that these women carry social disadvantage into motherhood, with the potential of continuing the cycle of deprivation. There is a case for increasing our attention on this group, which can be readily accessed by maternity and early years' services.

\section{Strengths and limitations of this study}

Nationally representative sample.

- Potential selection bias against mothers who had been in care and whose own children had been taken into care.

- Capture of adults who spent some of their childhood looked after by local authorities.

\section{INTRODUCTION}

Children in the public care system are an important group for public health action. In the UK, although legislation differs between the nations, looked-after children (also called children in care) are generally children whose parental responsibilities lie with the local authority, or are shared between parents and the local authority. These parental responsibilities may result in a variety of care arrangements such as foster care, placement in a children's home, or being placed with relatives. In the year ending March 2013, there were approximately 68110 looked-after children in England $(57 / 10000 \text { children })^{1}{ }^{2}$ and it has been estimated that during their childhood, around $3 \%$ of children in England and Wales had spent some time in care. ${ }^{3}$ These children often come from vulnerable households, and have many risk factors for poor social, educational and health outcomes. ${ }^{2}{ }^{4}$ Many of these health, social and psychological difficulties are related to the reasons for the child entering the care system. Sixty-two per cent of these children entered the care system due to abuse or neglect, and for 3\% of looked-after children, their own health problems led to them entering into care. ${ }^{2}$ It is likely that these disadvantages continue into adult life for many of these children. ${ }^{5}$ Despite these health and 
social disadvantages, there is very little evidence on the health status of this group. They are an underrepresented group in research as they are a highly mobile group, with issues of parental consent making enrolment into research studies difficult. ${ }^{6}$

Few studies have used nationally representative samples focusing on health outcomes over the life course of children who have been in care. ${ }^{1}{ }^{4}{ }^{5}$ Even fewer have investigated outcomes during pregnancy and early motherhood. ${ }^{7}$ In particular, whether mothers with a history of time spent in care have adverse maternal and pregnancy outcomes is currently unknown.

Pregnancy and early motherhood is an important stage in the life cycle: a time when women have a high level of contact with health and social care services. As a consequence, there is potential to identify high-risk women and provide interventions to improve pregnancy outcomes. ${ }^{8}$ This may be particularly relevant to adults who have previously been in care and who may have had a reduction in residential stability leading to disjointed health service access and reduced exposure to health advice and information. Measures have been proposed to improve outcomes for socially disadvantaged women such as multiagency working, tailored antenatal services, community-based continuity of care schemes and Family Nurse Partnerships for young mothers. ${ }^{9} 10$

Although previous work has looked at the associations between sexual risk behaviours and a history of time in care, very little evidence is available on the health status and maternal outcomes of these women. Previous research has shown that girls who have been in care have worse sexual health outcomes than girls who have never been in care. Girls who have been in care have a greater risk of teenage pregnancy, an earlier age at first intercourse and an increased number of sexual partners compared to girls who had not spent any time in the care system. ${ }^{11-15}$ In addition to a higher risk of teenage pregnancy and an increased number of sexual partners, Hobcraft ${ }^{15}$ found that girls who had been in care were at an increased risk of factors relating to social exclusion, such as no qualifications, homelessness and poor-quality housing.

In a review of maternal predictors for child health status, emotional well-being and educational attainment, Keirnan and Mensah ${ }^{7}$ found that mothers who had been in care before the age of 17 were more likely to report that their children were in fair or poor health rather than good or excellent health, compared to mothers who had not lived away from home. As far as we are aware, investigation of maternal and pregnancy outcomes while accounting for possible confounding factors such as socioeconomic class and maternal education has not previously been published.

The early years have been shown to be crucial for positive child development. We chose to focus on maternal indicators and behaviours that are likely to have an impact on child physical and mental well-being: smoking during pregnancy, low birth weight, breastfeeding initiation and symptoms of maternal depression. Smoking during pregnancy can lead to poor outcomes for mothers as well as for babies. ${ }^{16}$ Low birth weight is associated with worse childhood, and worse adult health and social outcomes, and is thought to be influenced by biological as well as social factors. ${ }^{17-19}$ The prevention of low birth weight through health and social interventions in order to reduce health inequalities at an intergenerational level is an important goal of public health. Maternal depression is associated with impaired mother-infant attachment, and children of depressed mothers are at a greater risk of deficits in social and cognitive function, along with being at a greater risk of psychopathology in later life. ${ }^{20-22}$ Despite breastfeeding having short-term and long-term health benefits for mother and baby, ${ }^{23}$ the UK has one of the lowest rates of breastfeeding worldwide, especially in young, white women from disadvantaged social groups. ${ }^{24}$

We compared the sociodemographic and health profiles of mothers who had been in care as a child with either foster parents or in a children's home to mothers who had not. We also looked at the relationship between the mothers who had been placed with foster parents or in a children's home with the likelihood of the following selected outcomes: smoking during pregnancy, birth weight, the presence of symptoms of maternal depression and the uptake of breastfeeding.

\section{METHODS}

\section{Millennium Cohort Study}

The Millennium Cohort Study is a nationally representative cohort study of 18818 infants from 18553 families born in the UK. ${ }^{25} \mathrm{~A}$ random two-stage sample of all infants born in the UK between 2000 and 2002, and who were alive and residents in the UK at 9 months was drawn from the Department of Social Security Child Benefit Registers. Children born in England and Wales were recruited between September 2000 and August 2001, and children born in Scotland and Northern Ireland were recruited between November 2000 and January 2002. Child Benefit Registers cover virtually all children, but excludes those whose residence status is either uncertain or temporary. Children who had died within the first 910 months of life were excluded. These children are estimated to be less than $1 \%$ of all births. ${ }^{26}$ The study used stratified sampling by electoral ward, with oversampling to ensure adequate representation of families living in poverty and those living in areas with high ethnic minority populations. Parents and guardians were interviewed by trained interviewers to capture sociodemographic and health information when their children were 9 months old, with subsequent follow-up at 3,5 and 7 years.

This study was a cross-sectional survey using the baseline questionnaire (9 months postnatally) of the Millennium Cohort Study.

\section{Time spent in care as a child}

The definition of a looked-after child or a child in care varies between countries due to national legislation. In 
this cohort, mothers were asked the question: "Before the age of 17 , did you spend any time living away from both of your parents?" If they answered yes, they were asked to indicate the nature of the time spent away from home and the amount of time they had spent away. Parents who had spent time in a children's home or with foster parents, run by either a local authority or a charitable organisation, were coded as having been in care. This group included women who were not sure whether their placement was managed by the local authority or any another organisation. Although children's homes and foster placements can be run by voluntary societies, the responsibility for the child still lies with the local authority. ${ }^{27}$ We classed mothers who had spent some amount of time in foster care or a children's home under the 'exposed' group. The comparison ('unexposed') group consisted of all mothers who had answered 'no' to the question: "Before the age of 17, did you spend any time living away from both of your parents?", or who had only spent time in a boarding school, prison or young-offenders' institution, or with relatives. Mothers who did not answer the question or who indicated that they were unsure of their answer were excluded.

\section{Breastfeeding}

Mothers were asked if they ever tried to breastfeed their cohort baby. If they answered yes, they were asked when they had last given their baby breast milk. Their answer was converted into breastfeeding duration, and then categorised into: 'never', 'less than 2 months' 'over 2 and less than 4 months' and 'over 4 months'. The information was also coded into a binary category of 'never breastfed' and 'ever breastfed'.

\section{Smoking during pregnancy}

Maternal smoking was coded as 'current non-smoker', 'smoked during pregnancy' or 'gave up smoking during pregnancy'. These categories were recoded as a binary outcome of 'smoked during pregnancy' and 'did not smoke during pregnancy'.

\section{Symptoms of depression}

Symptoms of depression were measured using 9 questions of the validated Malaise Inventory, ${ }^{28} 29$ a tool used within the Millennium Cohort Study, to provide a measure of depression or psychological distress. ${ }^{30}$ It is a self-report tool phrased in plain language. There is no specified time frame over which participants are asked to report their symptoms, but the emphasis is on the recent past.

\section{Birth outcomes}

Information on a baby's birth weight, gestation and delivery method was obtained by self-reporting. Previous studies have shown that there is good agreement between mothers' self-report of baby's birth weight, gestation and mode of delivery compared to hospital records. ${ }^{31-33}$
Birth weight was classified as $\geq 2.5 \mathrm{~kg}$ ('normal') or $<2.5 \mathrm{~kg}$ ('low'). Gestation was recorded in weeks and classified as $<28,28-32,33-36$ or $\geq 37$ weeks. The mode of delivery was categorised as 'normal', 'instrumental' or 'caesarean'.

\section{Sociodemographic factors}

Ethnicity was analysed as 'white' or 'other ethnic group'. Parity was the number of children the mother had (including the cohort member) and was coded as 1, 2, 3 or $>3$ children. Family status was categorised as 'lone parent', 'cohabiting' or 'married'.

Household socioeconomic class was measured by taking the occupation of the parent with the highest socioeconomic position according to the four UK National Statistics socioeconomic categories. Household income was calculated from the self-reported data on the questionnaire. Mother's education was determined by the highest attainment of a National Vocational Qualification or equivalent group. These qualifications were grouped as follows: 'higher' (bachelor's degree or equivalent), 'medium' (end of schooling at age 18, A Level or equivalent), 'lower' (end of compulsory schooling at age 16, General Certificate of Secondary Education (GCSE) or equivalent) or others.

\section{Inclusion and exclusion criteria}

The Millennium Cohort Study did not recruit families if the child had been taken into care at the time of initial assessment. One study participant, who withdrew consent after the study began, was excluded.

For this analysis, mothers were included if they were the birth mother of the Millennium Cohort Study participant. Mothers who did not answer the question of whether they lived away from home were excluded, as were mothers who answered the question as "I don't know".

\section{Statistical analysis}

First, we compared the following characteristics of the 'exposed' with 'unexposed' groups using the $\chi^{2}$ statistic: age at delivery, ethnic group, social class, household income, education, family status, parity, smoking during pregnancy, symptoms of depression, mode of delivery, gestational age, birth weight and duration of feeding.

We then used logistic regression to estimate ORs for a history of time spent in care and the outcomes of smoking during pregnancy, birth weight, breastfeeding initiation and symptoms of depression, with adjustment for potential confounding factors. A plausible model was developed based on background literature and included the following potential confounders: age at delivery, ethnic group, social class, household income and education. Previous evidence suggests that these factors are associated with poor perinatal outcomes, ${ }^{34}$ although there has been very little previous evidence on how factors relating to time in care manifest in maternal and neonatal outcomes. All of these potential confounders 
were significantly associated with the outcome (indicated by Wald, $\mathrm{p}<0.05$ ) after controlling for other factors in the model. Ethnicity was subsequently removed as its inclusion did not have an appreciable effect on the result, and its removal appeared to make the model more robust with narrower CIs.

For birth weight, the same potential confounders were considered together with gestational age and smoking during pregnancy. The following variables were significantly associated with the outcome (indicated by Wald, $\mathrm{p}<0.05)$ after controlling for other factors in the model: gestational age, education, ethnicity and maternal age. As smoking during pregnancy is likely to be in the causal chain of low birth weight, the model was considered with and without this variable to see to what extent the effect on birth weight is mediated by smoking.

The 'unexposed' group was used as the reference for these analyses.

For univariable analysis, those with missing outcomes of smoking during pregnancy, low birth weight and any breastfeeding following birth were excluded (7 $(0.04 \%)$, $21(0.1 \%)$ and $4(0.02 \%)$, respectively); all these excluded women were from the 18201 'unexposed' group. However, 726 women were excluded due to missing data on symptoms of depression (Malaise Inventory score). Women who had been in care were not more likely to have missing data in this variable than those who had not been in care. In those who had spent some of their childhood in care, 11 of the 291 women had missing data (3.9\%). There were no statistically significant differences between those who had missing data and those who did not in terms of age, income, social class and education. Of the women who had not spent any time in care, 715 of the 18201 women had missing data for symptoms of depression $(4.0 \%)$. Those who had missing data were more likely to be in a lower social class, have a lower income and to have lower or no qualifications.

For multivariable analysis, a complete case analysis was undertaken. Those excluded due to missing data were less than $10 \%$ of the cohort, with resulting sample size ranging from 16351 to 18238 (table 4).

All analyses took into account the clustered stratified study design by using the survey commands in Stata V.13.0. ${ }^{35}$ Reported $p$ values and CIs account for clustering, and estimates of proportions and ORs are weighted by sampling weights. ${ }^{36}$

\section{RESULTS}

\section{Description of the cohort}

There were 18552 respondents of the baseline interview of the Millennium Cohort Study. Fifty-seven respondents, who were not the natural mothers of the cohort baby, were excluded, as were three interviewees who did not have data relating to their time in care history. Therefore, our study population included 18492 natural mothers.

In the study population, there were 291 mothers who reported spending time in care as a child, which was
Table 1 Distribution of time spent in care by the 291 mothers who reported being in care

\begin{tabular}{lcl}
\hline Time in care & Frequency & Per cent \\
\hline Less than 3 months & 38 & 13 \\
3 months to 1 year & 35 & 12 \\
1-2 years & 42 & 14 \\
2-5 years & 90 & 31 \\
5-10 years & 44 & 15 \\
>Over 10 years & 42 & 15 \\
Total & 291 & \\
\hline
\end{tabular}

$1.6 \%$ of the cohort (95\% CI 1.3 to 1.8 ). Of the mothers who had reported spending time in foster care or in a children's home, $75 \%$ spent a year or more in care (see table 1).

These mothers were born in previous decades, with $5 \%$ born after 1980, 42\% between 1970 and 1980, 50\% between 1960 and 1970 and 4\% born before 1960 . Mothers who had been in care were younger, less likely to achieve a high social class, less likely to have a high household income and less likely to have achieved a high level of education, compared with the rest of the cohort (table 2). They were also more likely to be a single parent, to have a larger family and to smoke during their pregnancy (table 3). These differences were all statistically significant at the $5 \%$ level. There was no statistically significant association between ethnic group and reporting spending time in care. Although their babies were more likely to be born by normal vaginal delivery, there were no statistically significant differences in the gestation at delivery when compared to non-exposed women (table 3 ).

\section{Multivariable analysis}

Table 4 shows the ORs for the association between having been in care and smoking during pregnancy, breastfeeding and symptoms of postnatal depression. Women who had been in care were more likely to smoke during pregnancy (OR 3.0) compared with women who had not been in care, even after adjusting for possible confounding factors. Their babies were more likely to have a low birth weight (OR 1.8), although this effect was not statistically significant after controlling for confounding factors. They were also less likely to initiate breastfeeding compared with women who had not been in care, although again, this effect was not statistically significant after adjusting for other factors (table 4). Women who had been in care were more likely to have symptoms of depression (OR 2.0), even after controlling for possible confounding factors.

\section{DISCUSSION}

\section{Summary of findings}

In our study, which represents the mothers of babies born in the UK during 2001-2002, 1.6\% of women in 
Table 2 Sociodemographic characteristics of women with and without a history of being in care

\begin{tabular}{|c|c|c|c|}
\hline Characteristic & $\begin{array}{l}\text { Time in care } \\
\text { Yes }(n=291) \\
\text { Per cent }(95 \% \mathrm{CI})\end{array}$ & $\begin{array}{l}\text { No }(n=18201) \\
\text { Per cent }(95 \% \mathrm{Cl})\end{array}$ & p Value \\
\hline Age at delivery & & & $<0.001$ \\
\hline$<20$ & $11.1(7.7$ to 15.9$)$ & 4.9 (4.4 to 5.3$)$ & \\
\hline 20-29 & 59.3 (52.3 to 65.9$)$ & 41.3 (39.6 to 43.0$)$ & \\
\hline 30-39 & 28.6 (22.6 to 35.5$)$ & $50.3(48.5$ to 52.1$)$ & \\
\hline$\geq 40$ & $1.0(0.3$ to 3.9$)$ & 3.6 (3.3 to 4.0$)$ & \\
\hline Ethnic group & & & 0.52 \\
\hline White & 88.3 (82.3 to 92.5$)$ & 86.8 (84.3 to 88.9$)$ & \\
\hline Other ethnic group & 11.7 (7.5 to 17.7$)$ & $13.2(11.1$ to 15.7$)$ & \\
\hline Social class & & & $<0.001$ \\
\hline Managerial & 17.3 (18.8 to 24.6$)$ & 44.9 (42.7 to 47.1$)$ & \\
\hline Intermediate occupations & 16.0 (11.5 to 21.8$)$ & 19.6 (18.8 to 20.5$)$ & \\
\hline Routine and manual & 51.3 (44.5 to 58.0$)$ & 30.8 (29.1 to 32.6$)$ & \\
\hline Never worked and long term unemployed & 15.4 (11.2 to 20.9$)$ & 4.6 (4.0 to 5.4$)$ & \\
\hline Household income & & & $<0.001$ \\
\hline$<£ 10400$ & 48.4 (41.3 to 55.4$)$ & 22.1 (20.7 to 23.6 ) & \\
\hline$£ 10400-£ 20800$ & 35.2 (28.7 to 42.2$)$ & 31.9 (30.3 to 33.4$)$ & \\
\hline$£ 20800-£ 31200$ & 9.5 (6.0 to 14.9$)$ & 22.1 (20.9 to 23.3) & \\
\hline$£ 31200-£ 52000$ & 5.3 (2.5 to 10.9$)$ & 17.0 (15.8 to 18.3$)$ & \\
\hline$>£ 52000$ & 1.7 (0.7 to 4.2$)$ & 7.0 (5.6 to 8.6$)$ & \\
\hline Education & & & $<0.001$ \\
\hline Higher & 11.7 (7.2 to 18.5$)$ & 32.9 (30.7 to 35.1$)$ & \\
\hline Medium & 7.5 (4.6 to 12.1$)$ & $14.3(13.6$ to 15.0$)$ & \\
\hline Lower & 37.4 (31.6 to 43.6$)$ & 38.0 (36.3 to 39.7$)$ & \\
\hline Other & 4.0 (1.8 to 8.7$)$ & $2.4(2.1$ to 2.8$)$ & \\
\hline Lone parent & $10.4(6.81$ to 1525$)$ & 3.5 (3.0 to 4.1$)$ & $<0.001$ \\
\hline
\end{tabular}

this cohort had spent some of their childhood in the care system, either with foster parents or in a children's home. The majority of these women had spent a year or more in care. The mothers in our study who had spent some of their childhood as a looked-after child were disadvantaged in terms of social and economic factors when compared to the mothers who had not. They were more likely to smoke during their pregnancy and have symptoms of depression. This likelihood persisted after adjusting for confounding factors. In univariable analysis, they were more likely to have a low-birthweight baby and less likely to breastfeed, but this effect did not persist after adjusting for confounding factors.

These results suggest that women with a history of time in foster care or in a children's home carry social disadvantage into adulthood and motherhood.

\section{Comparison with other studies}

As far as we are aware, this study is one of the first studies to look at health status and maternal outcomes of pregnant women who have previously been in care. The links between social disadvantage and being in care, and the links between social disadvantage and poor maternal outcomes are well documented. It is not surprising that the findings of this study show that being in care is associated with social disadvantage and adverse maternal outcomes. Previous studies have shown that children who have been in care are more likely to become teenage parents.

Compared to previous estimates of the number of children in England in care at any given time, our estimate is considerably lower. Simkiss et $a \hat{l}$ suggest that $3 \%$ of children in the UK have spent some time in care. Our estimate may be low because we have missed many mothers who have previously been in care, which could be due to them declining to take part, or because their children had been taken into care. If this is the case, then these mothers are likely to be different from those who had agreed to the recruitment of their children.

The worse birth outcomes in terms of birth weight and prematurity found in the exposed group could be in part a result of the association between antenatal smoking with low birth weight and prematurity, ${ }^{37}$ and the high rate of antenatal smoking in this group. Younger mothers are more likely to have an unassisted birth ${ }^{38}$ and we postulate that the higher proportion of normal deliveries seen in the exposed group is associated with the lower average age of women in this group. There is likely to be an association between social class and mode of delivery, but previous studies are conflicting in describing this effect. While some studies find an increased rate of caesarean section with area level deprivation, ${ }^{39} 40$ others find a more complicated relationship between age-at-first delivery, education, social class and mode of delivery, with primigravida women from a lower socioeconomic class 
Table 3 Pregnancy and neonatal characteristics of women with and without a history of being in care

\begin{tabular}{|c|c|c|c|}
\hline Characteristic & $\begin{array}{l}\text { Time in care } \\
\text { Yes }(n=291) \\
\%(95 \% \mathrm{Cl})\end{array}$ & $\begin{array}{l}\text { No }(n=18201) \\
\%(95 \% \mathrm{Cl})\end{array}$ & p Value \\
\hline Parity & & & $<0.001$ \\
\hline 1 & 28.7 (22.6 to 35.6$)$ & 41.4 (40.3 to 42.5$)$ & \\
\hline 2 & 33.9 (28.2 to 40.2$)$ & 35.8 (34.9 to 36.7$)$ & \\
\hline 3 & 17.7 (13.6 to 22.7$)$ & 15.0 (14.3 to 15.7$)$ & \\
\hline$>3$ & 19.7 (14.6 to 26.2$)$ & 7.9 (7.3 to 8.5$)$ & \\
\hline \multicolumn{4}{|l|}{ Smoking during pregnancy } \\
\hline Kept smoking during pregnancy & $58.0(50.5$ to 65.1$)$ & 20.8 (19.6 to 22.1$)$ & $<0.001$ \\
\hline Gave up & 14.9 (10.4 to 21.1$)$ & $13.3(12.5$ to 14.1$)$ & \\
\hline Never smoked & 27.1 (21.5 to 33.5$)$ & 65.9 (64.6 to 67.3$)$ & \\
\hline Symptoms of depression & & & $<0.001$ \\
\hline Yes & 31.3 (25.4 to 37.8$)$ & $13.4(12.7$ to 14.1$)$ & \\
\hline No & 68.7 (62.2 to 74.6$)$ & 86.6 (86.0 to 87.3$)$ & \\
\hline Mode of delivery & & & 0.03 \\
\hline Normal & 76.5 (70.0 to 81.8$)$ & 67.7 (66.7 to 68.8$)$ & \\
\hline Instrumental & 7.6 (4.8 to 11.9$)$ & $10.3(9.7$ to 11.0$)$ & \\
\hline Caesarian & 15.9 (11.5 to 21.6$)$ & 22.0 (21.2 to 22.8$)$ & \\
\hline Gestational age, weeks & & & 0.86 \\
\hline$<28$ & $0.3(0.1$ to 1.0$)$ & $0.3(0.2$ to 0.4$)$ & \\
\hline 28-32 & $1.5(0.5$ to 4.5$)$ & $1.2(1.0$ to 1.3$)$ & \\
\hline $33-36$ & 6.9 (4.2 to 11.2$)$ & 6.3 (5.9 to 6.8$)$ & \\
\hline$\geq 37$ & 91.2 (86.9 to 94.2$)$ & 92.2 (91.7 to 92.7$)$ & \\
\hline Birth weight, kg & & & 0.009 \\
\hline$\geq 2.5$ & 88.5 (83.2 to 92.3$)$ & 93.3 (92.9 to 93.7$)$ & \\
\hline$<2.5$ & 11.5 (7.7 to 16.8$)$ & $6.7(6.3$ to 7.1$)$ & \\
\hline \multicolumn{4}{|l|}{ Duration of breastfeeding, months } \\
\hline Never breastfed & 46.5 (39.5 to 53.6$)$ & 30.3 (28.6 to 32.0$)$ & $<0.001$ \\
\hline Less than 2 & 27.8 (22.2 to 34.3$)$ & 26.4 (25.3 to 27.5$)$ & \\
\hline $2-4$ & 8.9 (5.9 to 13.3$)$ & 10.6 (10.1 to 11.2$)$ & \\
\hline More than 4 & 16.8 (12.0 to 22.9$)$ & 32.7 (30.7 to 34.8$)$ & \\
\hline
\end{tabular}

having a higher rate of planned caesarean section or instrumental delivery ${ }^{41}$ while still others have found that individuals with a higher socioeconomic class have a higher rate of elective caesarean section, those with a lower socioeconomic class have a higher rate of emergency caesarean section. ${ }^{42}$

\section{Strengths and limitations}

A strength of this study is the use of Millennium Cohort Study data, a nationally representative sample which ensured adequate representation from socially disadvantaged groups and people from ethnically diverse backgrounds. Using this cohort allowed us to capture women who had previously been in care during their adult lives, which can be otherwise difficult to do.

The amount of missing data was small: except in the multivariable analysis using the Malaise Inventory score as an outcome, the negligible amount of missing data would be unlikely to affect the results. For the outcome of symptoms of depression, $3.9 \%$ of the data was missing and it is possible that the worse social characteristics of the women without information on their Malaise Inventory score may have led to a small increase in the estimation of the effect of being in care in the adjusted model.
A major limitation of this study is that a large number of women with a history of being in care may not be included in the MCS due to their not agreeing to take part or being ineligible because their own children had been taken into care. Furthermore, information on the childhood socioeconomic status of the mothers was not available.

However, although we can compare our prevalence to estimates of children currently in care, it is not possible to obtain estimates of how many women of child-bearing age, at the time of our cohort, may have been in care during their childhoods without prevalence data of children in care from the 1960 s to the $1990 \mathrm{~s}$. Therefore, we are unable to say what the likely proportion of women who would have been excluded would be. However, it is possible that women who were excluded due to having their own children taken into care may be more likely to have had worse social outcomes than those who entered the cohort. We would assume that if the data on these women had been captured, the results of this study would have been more extreme. A systematic review of the characteristics of families whose children were taken into care showed that a low-socioeconomic status was the factor most associated with this outcome. ${ }^{43}$ This systematic review noted a large variation by country in the factors associated 
Table 4 Unadjusted and adjusted ORs $(95 \% \mathrm{Cl})$ for smoking during pregnancy, low birth weight, any breastfeeding and symptoms of depression among mothers according to a history of being in care

\begin{tabular}{|c|c|c|c|}
\hline & $\begin{array}{l}\text { Percentage* of }^{*} \\
\text { participants (n) }\end{array}$ & Unadjusted (95\% Cl) & Adjusted $(95 \% \mathrm{Cl})$ \\
\hline Mother smoked during pregnancy & & $n=18485$ & $\mathrm{n}=16902$ \\
\hline Any time spent in care & $58.0(173)$ & 5.3 (3.9 to 7.1$)$ & $3.0(2.1$ to 4.3$) \dagger$ \\
\hline Low birth weight & & $n=18471$ & $\mathrm{n}=18238$ \\
\hline No time spent in care & $6.7(1293)$ & 1 & 1 \\
\hline Any breastfeeding & & $\mathrm{n}=18488$ & $\mathrm{n}=16905$ \\
\hline No time spent in care & $69.7(11988)$ & 1 & 1 \\
\hline Any time spent in care & $53.5(156)$ & $0.5(0.4$ to 0.7$)$ & $1.1(0.7$ to 1.4$) \dagger$ \\
\hline Symptoms of depression & & $\mathrm{n}=17766$ & $\mathrm{n}=16351$ \\
\hline No time spent in care & $13.4(2566)$ & 1 & 1 \\
\hline Any time spent in care & $31.3(87)$ & $2.9(2.2$ to 4.0$)$ & $1.98(1.4$ to 2.7$) \dagger$ \\
\hline
\end{tabular}

with families requiring children to be placed in care, and that only one study was found from the UK. This and subsequent studies suggest that in the UK, children who have been taken into care are more likely to have had mothers who were younger, to have a history of substance misuse or mental illness, to live in a deprived neighbourhood, to be from a lower social class, and to live in overcrowded or rented accommodation. ${ }^{344}$

\section{Potential mechanisms and policy implications}

The population of this study is women born between the 1960s and mid-1980s, and their children who are now 13-14 years old. The findings of this study have relevance to these children as they enter adolescence and adulthood, as evidence suggests that activity in the early years can have lasting effects on health and psychosocial functioning. ${ }^{45-47}$ Unfortunately, the outcomes for looked-after children in the UK remain poor, during their childhood and also when they enter adult life. ${ }^{5} 4849$ The increased policy focus on the early years, education and integrated care in recent times may have helped to improve outcomes for these children. ${ }^{50}$

From this study it is not possible to determine whether the social disadvantage is a direct antecedent to being in care, or whether being in care led to subsequent social disadvantage. The question remains whether being in care confers a disadvantage in terms of maternal behaviours and outcomes over and above the social and economic disadvantage.

However, one may argue that it is not necessarily helpful to make this distinction. One of the aims of the social care system is to reduce the social disadvantage that the child experiences on entering care, and idealistically improve the child's life circumstances in order that he or she has a better start in life. The UK still has a long way to go in reducing the long-term disadvantage experienced by children in care. Of particular concern is the evidence presented here that suggests that this disadvantage persists to child-bearing age and is associated with maternal behaviours and outcomes that have the potential to affect the health and well-being of these parents' children. In addition to the legacy of early and continuing social disadvantage such as low-household income, loweducational attainment and reduced-employment opportunities, there are aspects of care itself that may have an effect on the maternal outcomes studied, such as residential instability, disrupted parental attachments and difficulties in resolving history when faced with having children of one's own. ${ }^{12} 51-53$

It is known that maternal smoking, birth weight, depression and breastfeeding rates are potentially modifiable outcomes with appropriate screening, education and support from healthcare professionals. Tools exist to screen for and identify perinatal depression, and there are ways that women with depression can be supported and treated. ${ }^{54}$ Likewise, smoking in pregnancy and breastfeeding can be asked about and women who would like to change their current behaviours can be supported to change. ${ }^{24}{ }^{55-57}$ Historically and recently, improving birth weight is a public health priority in the UK. ${ }^{58} 59$ Pregnancy and early motherhood are times when women who are often otherwise healthy have a large amount of contact with healthcare services. These results suggest that it may be worthwhile to pay particular attention to women who have a history of being in care when they present to health and social care services during pregnancy and early motherhood. Currently, a history of time in care is not part of the routine information collected during prenatal visits. It has been suggested that a wider range of sociodemographic information should be collected in order to create a deeper understanding of the individual mother's needs. ${ }^{7}$ 
The best way to use this information for policy change is yet to be determined. Interventions aimed at improving the educational and emotional outcomes for looked-after children are varied, despite difficulties in producing sustained improvement. Educational and emotional outcomes for looked-after children in European countries such as Denmark, Germany and Norway are better than those in the UK. The use of the social pedagogy approach has been accredited for some of these differences. This approach emphasises emotional warmth and personal development. Information on how the health and emotional well-being of looked after children can perpetuate cycles of deprivation may add to this body of research. ${ }^{60}$

\section{Future research}

There has been an increased focus on the outcomes for children in care, particularly over the past decade. ${ }^{61} 62$ Therefore, outcomes for children in care could be very different for women previously in care who are pregnant currently, as compared to those pregnant 10 years ago. It would be useful to look at the current health outcomes of mothers previously in care and those of their children in order to see if presently there are inequities, and whether these inequities are reducing.

Information is currently collected by the Department of Education on the educational outcomes of children in care, and this research has been used to target interventions at increasing their educational attainment. ${ }^{63}$ Berridge $^{64}$ argues that focusing on these educational targets alone is not enough, and that a theory and approach that encompass a wide view of the challenges faced by children in care are needed. We argue that the mental and physical health of looked-after children during pregnancy is an area that should be added as a piece of this policy puzzle.

\section{CONCLUSIONS}

Findings from the Millennium Cohort Study indicate that mothers with a history of spending time in care are more disadvantaged socially and economically when compared to other mothers even after they have left care and during their children's infancy. We looked in more detail at smoking during pregnancy, low birth weight, symptoms of depression in early motherhood and whether breastfeeding was initiated, and found that mothers who had been in care were more likely to smoke during pregnancy and to have symptoms of depression. This is consistent with previous research suggesting that social and health disadvantages faced by children in care persist into adult life.

Contributors SKB, MAQ and RG made substantial contributions to conception and design, acquisition of data and interpreted the data and revised the article critically for important intellectual content; and approved of the version to be published. SB performed the initial analysis of the data and wrote the first draft of the article. SKB, RG and MAQ.

Funding This research received no specific grant from any funding agency in the public, commercial or not-for-profit sectors.
Competing interests None.

Ethics approval This research involved secondary analysis of the MCS and therefore did not require ethical approval. Ethical approval for the Millennium Cohort Study was granted from the multicentre research ethics committee.

Provenance and peer review Not commissioned; externally peer reviewed.

Data sharing statement The datasets are available on the UK Data Archive. Further information about the study and data can be found at http://www.cls. ioe.ac.uk/

Open Access This is an Open Access article distributed in accordance with the Creative Commons Attribution Non Commercial (CC BY-NC 4.0) license, which permits others to distribute, remix, adapt, build upon this work noncommercially, and license their derivative works on different terms, provided the original work is properly cited and the use is non-commercial. See: http:// creativecommons.org/licenses/by-nc/4.0/

\section{REFERENCES}

1. Martin A, Ford T, Goodman R, et al. Physical illness in looked-after children: a cross-sectional study. Arch Dis Child 2014;99:103-7.

2. Department of Education. Children looked after in England (including adoption and care leavers) year ending 31 March 2013. London: Office of National Statistics, 2014.

3. Simkiss DE, Spencer NJ, Stallard N, et al. Health service use in families where children enter public care: a nested case control study using the General Practice Research Database. BMC Health Serv Res 2012;12:65.

4. Department of Education. Outcomes for children looked after by local authorities in England, as at 31 March 2013. London: Office of National Statistics, 2014.

5. Viner RM, Taylor B. Adult health and social outcomes of children who have been in public care: population-based study. Pediatrics 2005;115:894-9.

6. Ford $\mathrm{T}$, Vostanis $\mathrm{P}$, Meltzer $\mathrm{H}$, et al. Psychiatric disorder among British children looked after by local authorities: comparison with children living in private households. Br J Psychiatry 2007;190:319-25.

7. Keirnan K, Mensah F. Maternal indicators in pregnancy and childhood infancy that signal future outcomes for children's development, behaviour and health: evidence from the Millennium Cohort Study. Department of Social Policy and Social Work, University of York, 2010.

8. National Institute for Health and Clinical Excellence (NICE). Pregnancy and complex social factors: a model for service provision for pregnant women with complex social factors-guidance (CG110). 2010

9. Department of Health. Maternity Standard, National Service Framework for Children, Young People and Maternity Services, 2004.

10. Department of Health. Healthy lives, healthy people: our strategy for public health in England. Cm. Norwich: Stationery Office, 2010:96.

11. Carpenter SC, Clyman RB, Davidson AJ, et al. The association of foster care or kinship care with adolescent sexual behavior and first pregnancy. Pediatrics 2001;108:E46.

12. Svoboda DV, Shaw TV, Barth RP, et al. Pregnancy and parenting among youth in foster care: a review. Child Youth Serv Rev 2012;34:867-5.

13. Vinnerljung B, Franzén E, Danielsson M. Teenage parenthood among child welfare clients: a Swedish national cohort study of prevalence and odds. J Adolesc 2007;30:97-116.

14. Polit DF, Morton TD, White CM. Sex, contraception and pregnancy among adolescents in foster care. Fam Plann Perspect 1989;21:203-8.

15. Hobcraft J. Intergenerational and life-course transmission of social exclusion: influences and childhood poverty, family disruption and contact with the police. Centre for Analysis of Social Exclusion, LSE, 1998.

16. Whitworth M, Dowswell T. Routine pre-pregnancy health promotion for improving pregnancy outcomes. Cochrane Database Syst Rev 2009;(4):CD007536.

17. Aizer A, Currie J. The intergenerational transmission of inequality: maternal disadvantage and health at birth. Science 2014;344:856-1.

18. Kramer MR. Determinants of low birth weight: methodological assessment and meta-analysis. Bull World Health Organ 1987;65:663-737.

19. Barker DJ. Fetal and infant origins of adult disease. London: BMJ Publications, 1992. 
20. Paulson JF, Dauber S, Leiferman JA. Individual and combined effects of postpartum depression in mothers and fathers on parenting behavior. Pediatrics 2006;118:659-68.

21. Coyl DD, Roggman LA, Newland LA. Stress, maternal depression, and negative mother-infant interactions in relation to infant attachment. Infant Men Health J 2002;23:145-63.

22. Canadian Paediatric Society. Maternal depression and child development. Paediatr Child Health 2004;9:575-98.

23. National Institute for Health and Clinical Excellence (NICE). Maternal and child nutrition. NICE, 2008.

24. Dyson. Promotion of breast feeding initiation and duration: evidence into practive briefing. NICE, 2006.

25. Centre for Longitudinal Studies. The age 9 months survey of the MCS (2001-2002), 20.

26. Office of National Statistics. Infant and perinatal mortality 2001: health areas, England and Wales. Health Stat Q 2002;15:75-8.

27. Department of Education. Improving the adoption system and services for looked after children. Policy, 2014.

28. Rodgers B, Pickles A, Power C, et al. Validity of the Malaise Inventory in general population samples. Soc Psychiatry Psychiatr Epidemiol 1999;34:333-41.

29. McGee R, Williams S, Silva PA. An evaluation of the Malaise Inventory. J Psychosom Res 1986;30:147-52.

30. Centre for Longitudinal Studies. MCS user guide: Psychological, developmental and health inventories, 2012.

31. Tate AR, Dezateux C, Cole TJ, et al. Factors affecting a mother's recall of her baby's birth weight. Int J Epidemiol 2005;34:688-95.

32. Poulsen G, Kurinczuk JJ, Wolke D, et al. Accurate reporting of expected delivery date by mothers 9 months after birth. $J$ Clin Epidemiol 2011;64:1444-50.

33. Quigley MA, Hockley C, Davidson LL. Agreement between hospital records and maternal recall of mode of delivery: evidence from 12391 deliveries in the UK Millennium Cohort Study. BJOG 2007;114:195-200.

34. Marmot M, International Balzan Foundation. Fair society, healthy lives.

35. Stata Statistical Software: Release 13. College station, TX: StataCorp LP. [program], 2013.

36. Hanson K, ed. Millennium cohort study, first, second and third surveys: a guide to the datasets. 3rd edn. London: Centre for Longitudinal Studies, Institute of Education, 2008.

37. Cnattingius $\mathrm{S}$. The epidemiology of smoking during pregnancy: smoking prevalence, maternal characteristics, and pregnancy outcomes. Nicotine Tob Res 2004;6(Suppl 2):S125-S40.

38. Bayrampour $\mathrm{H}$, Heaman M. Advanced maternal age and the risk of cesarean birth: a systematic review. Birth 2010;37:219-26.

39. Barley K, Aylin P, Bottle A, et al. Social class and elective caesareans in the English NHS. BMJ 2004;328:1399.

40. Alves B, Sheikh A. Investigating the relationship between affluence and elective caesarean sections. BJOG 2005;112:994-96.

41. Essex HN, Green J, Baston $\mathrm{H}$, et al. Which women are at an increased risk of a caesarean section or an instrumental vaginal birth in the UK: an exploration within the Millennium Cohort Study. BJOG 2013;120:732-43.

42. Fairley L, Dundas $R$, Leyland $A H$. The influence of both individual and area based socioeconomic status on temporal trends in Caesarean sections in Scotland 1980-2000. BMC Public Health 2011;11:330.
43. Simkiss DE, Stallard N, Thorogood M. A systematic literature review of the risk factors associated with children entering public care. Child Care Health Dev 2013;39:628-42.

44. Bebbington A, Miles. The background of children who enter local authority care. Br J Soc Work 1989;19:349-68.

45. Dixon J. Young people leaving care: health, well-being and outcomes. Child Fam Soc Work 2008:13:207-17.

46. Barker DJ. The origins of the developmental origins theory. J Intern Med 2007;261:412-7.

47. Peruzzi A. From childhood deprivation to adult social exclusion: evidence from the 1970 british cohort study. Soc Indic Res 2014:1-19.

48. Department of Health. Statutory guidance on promoting the health and well-being of looked after children. 2009.

49. National Institute for Health and Clinical Excellence (NICE). Looked after children and young people, 2010.

50. Science BBo. Growing up in the UK: ensuring a healthy future for our children. British Medical Association, 2013.

51. Dregan A, Gulliford MC. Foster care, residential care and public care placement patterns are associated with adult life trajectories: population-based cohort study. Soc Psychiatry Psychiatr Epidemiol 2012;47:1517-26.

52. Pryce JM, Samuels GM. Renewal and risk: the dual experience of young motherhood and aging out of the child welfare system. $J$ Adolesc Res 2010;25:205-30.

53. Maxwell A, Proctor J, Hammond L. 'Me and my child': parenting experiences of young mothers leaving care. Adoption Fostering 2011;35:29-40.

54. Nylen KJ, Moran TE, Franklin CL, et al. Maternal depression: a review of relevant treatment approaches for mothers and infants. Infant Men Health J 2006;27:327-43.

55. National Institute for Health and Clinical Excellence (NICE). CG45 Antenatal and postnatal mental health: clinical management and service guidelines. 2010

56. National Institute for Health and Clinical Excellence (NICE). PH26 Quitting smoking in pregnancy and following childbirth. 2010.

57. Lumley J, Chamberlain C, Dowswell T, et al. Interventions for promoting smoking cessation during pregnancy. Cochrane Database Syst Rev 2009;(3):CD001055.

58. Health Development Agency. Prevention of low birth weight: assessing the effectiveness of smoking cessation and nutritional interventions. London: National Health Service, 2003.

59. (NICE) NlfHaCE. Clinical Commissioning Group Outcomes Indicator Set Rationale. 2014

60. Boddy J, Statham J, McQuail S, et al. Workign at the 'edges' of care? European models of support for young people and families: Thomas Coram Research Unit, Institute of Education. University of London, 2009.

61. Chief Secretary to the Treasury. Every child matters, 2003.

62. Polnay L, Ward $\mathrm{H}$. Promoting the health of looked after children. Government proposals demand leadership and a culture change. BMJ 2000;320:661-2.

63. Social Exclusion Unit. A better education for children in care. Social Exclusion Unit, 2003

64. Berridge D. Theory and explanation in child welfare: education and looked-after children. Child Fam Soc Work 2007;12:1-10. 